\title{
Motivation and Education: The Self-Determination Perspective
}

\author{
Edward L. Deci \\ University of Rochester \\ Robert J. Vallerand \\ University of Quebec at Montreal \\ Luc G. Pelletier \\ University of Ottawa \\ Richard M. Ryan \\ University of Rochester
}

\begin{abstract}
Self-determination theory (Deci \& Ryan, 1985, 1991), when applied to the realm of education, is concerned primarily with promoting in students an interest in learning, a valuing of education, and a confidence in their own capacities and attributes. These outcomes are manifestations of being intrinsically motivated and internalizing values and regulatory processes. Research suggests that these processes result in high-quality learning and conceptual understanding as well as enhanced personal growth and adjustment. In this article we also describe social-contextual factors that nurture intrinsic motivation and promote internalization, leading to the desired educational outcomes.
\end{abstract}

In their formative first two decades, individuals spend about $15,000 \mathrm{hr}$ in schools. Thus schools represent a primary socializing influence that has enormous impact on the course of people lives and, in turn, on society. Ideal school systems are ones that succeed in promoting in students a genuine enthusiasm for learning and accomplishment and a sense of volitional involvement in the educational enterprise. It is this interest and volition, we suggest, that lead students to display greater flexibility in

Requests for reprints should be sent to Edward L. Deci, Department of Psychology, University of Rochester, Rochester, NY 14627. 
problem solving, more efficient knowledge acquisition, and a strong sense of personal worth and social responsibility.

The central features of optimal learning are conceptual understanding and the flexible use of knowledge. In other words, understanding both the relations among facts and the ways to find or generate facts are the learning outcomes that we stress. The acquisition and retention of facts are important but are by no means enough for excellent education. Correspondingly, the central features of optimal adjustment are feeling good about oneself and acting volitionally to satisfy one's own needs while being attuned to and concerned about the social surround. Simply fitting in or complying with social demands is a nonoptimal form of adjustment and may even be counterproductive to personal and social development.

These broad learning and adjustment outcomes are what we seek to promote in schools, and although these outcomes are sometimes considered independent or even antithetical, a body of motivational research, guided largely by self-determination theory (e.g., Deci \& Ryan, 1985, 1991), has indicated that they are complementary when the school context stimulates certain kinds of motivation in its students. The highest quality of conceptual learning seems to occur under the same motivational conditions that promote personal growth and adjustment.

\section{SELF-DETERMINATION THEORY}

\section{Behavioral Regulation}

Most current theories of motivation have the concept of intention (e.g., Lewin, 1951) at their core. They are concerned with factors that promote (vs. fail to promote) people's understanding of behavior-outcome instrumentalities and engaging in efficacious behaviors to attain those outcomes. This conceptual distinction between motivated and amotivated actions - in other words, between intentional and nonintentional behaving - has been described in various terms. These include personal versus impersonal causality (Heider, 1958), voluntary responding versus helplessness (Seligman, 1975), and internal versus external locus of control (Rotter, 1966).

Unlike most other theories, however, self-determination theory makes an important additional distinction that falls within the class of behaviors that are intentional or motivated. It distinguishes between self-determined and controlled types of intentional regulation. Motivated actions are selfdetermined to the extent that they are engaged in wholly volitionally and endorsed by one's sense of self (Deci \& Ryan, 1991), whereas actions are controlled if they are compelled by some interpersonal or intrapsychic 
force. When a behavior is self-determined, the regulatory process is choice, but when it is controlled, the regulatory process is compliance (or in some cases defiance).

The dimension that ranges from being self-determined to being controlled in one's intentional responding has also been described using the concept of perceived locus of causality (deCharms, 1968; Ryan \& Connell, 1989). When a behavior is self-determined, the person perceives that the locus of causality is internal to his or her self, whereas when it is controlled, the perceived locus of causality is external to the self. The important point in this distinction is that both self-determined and controlled behaviors are motivated or intentional but their regulatory processes are very different. Further, as we show later, the qualities of their experiential and behavioral components are accordingly different.

\section{Human Needs}

Most current theories of motivation focus on goals or outcomes and on the instrumentalities that lead to these desired outcomes (e.g., Bandura, 1977; Dweck, 1986; Eccles, 1983). Such theories are concerned with the direction of behavior (i.e., with the processes that direct behavior toward desired outcomes), but they do not deal with the question of why certain outcomes are desired. Therefore, they fail to address the issue of the energization of behavior.

Unlike these other theories, self-determination theory does address the energization issue as well as the direction issue, and it does so by postulating about basic psychological needs that are inherent in human life. The theory focuses primarily on three such innate needs: the needs for competence, relatedness, and autonomy (or self-determination). Competence involves understanding how to attain various external and internal outcomes and being efficacious in performing the requisite actions; relatedness involves developing secure and satisfying connections with others in one's social milieu; and autonomy refers to being self-initiating and self-regulating of one's own actions.

There are several reasons why the concept of needs, when employed in a way that involves a small number of broad, innate needs, is useful (Deci, in press). First, it gives content to human nature; in other words, it addresses whether there are motivational universals in human beings. Second, it provides a basis for drawing together and integrating a range of phenomena that might not seem connected at a superficial level. Third, and most important to this discussion, it allows one to specify the contextual conditions that will facilitate motivation, performance, and development. Simply stated, notivation, performance, and development will be maximized within social contexts that provide people the opportunity to satisfy 
their basic psychological needs for competence, relatedness, and autonomy. Opportunities to satisfy any of these three needs contribute to people's being motivated (as opposed to amotivated); however, opportunities to satisfy the need for autonomy are necessary for people to be self-determined rather than controlled.

\section{Self-Determination: Intrinsic and Extrinsic Motivation}

Intrinsically motivated behaviors are engaged in for their own sake - for the pleasure and satisfaction derived from their performance. When intrinsically motivated, people engage in activities that interest them, and they do so freely, with a full sense of volition and without the necessity of material rewards or constraints (Deci \& Ryan, 1985). The child who reads a book for the inherent pleasure of doing so is intrinsically motivated for that activity. Intrinsically motivated behaviors represent the prototype of selfdetermination - they emanate from the self and are fully endorsed.

Extrinsically motivated behaviors, on the other hand, are instrumental in nature. They are performed not out of interest but because they are believed to be instrumental to some separable consequence. In early research on intrinsic and extrinsic motivation (e.g., Deci, 1971), the two forms of motivation appeared to be antagonistic, and thus extrinsically motivated behaviors were assumed not to be self-determined. More recently, however, theory and research have suggested that there are different types of extrinsically motivated behaviors and that these types differ in the extent to which they represent self-determined versus controlled responding (Ryan \& Connell, 1989). Deci and Ryan (1985) identified four types of extrinsic motivation: external, introjected, identified, and integrated forms of regulation. Their argument was built around the concept of internalization.

Internalization. Internalization is a proactive process through which people transform regulation by external contingencies into regulation by internal processes (Schafer, 1968). For example, a boy who is not interested in learning the capitals of states would not be intrinsically motivated to do so, and his learning would require contingent consequences such as praise from the teacher. Internalization is the process through which the regulation of the boy's geography learning could become internal and no longer require external contingencies. In self-determination theory, internalization is viewed as a motivated process. We believe (a) that people are inherently motivated (out of the three basic needs) to internalize and integrate within themselves the regulation of uninteresting activities that are useful for effective functioning in the social world and (b) that the extent to which the 
process of internalization and integration proceeds effectively is a function of the social context.

Optimal internalization results in regulations' being fully integrated into the self, although there are also less optimal forms of internalization (Ryan, 1991). Self-determination theory posits that the four types of extrinsic motivation result from the internalization process's having been differentially effective. The resulting regulatory styles thus fall at different points along an autonomy continuum that describes the extent to which they have been internalized and integrated.

External regulation. External regulation refers to behaviors for which the locus of initiation is external to the person, for example, the offer of a reward or the threat of a punishment. A student who does an assignment for teacher's praise or to avoid parental confrontation is externally regulated. The behavior is performed because of an external contingency, and these contingencies are considered the loci of initiation and regulation. External regulation represents the least self-determined form of extrinsic motivation.

Introjected regulation. Taking in but not accepting a regulation as one's own is the basis of introjected regulation. Such regulation involves internalized rules or demands that pressure one to behave and are buttressed with threatened sanctions (e.g., guilt) or promised rewards (e.g., selfaggrandizement). Introjected regulations, although within the person, are not part of the integrated self (Deci \& Ryan, 1991), so behavior regulated by introjects is not considered self-determined. A student who gets to class on time to avoid feeling like a bad person is regulated by introjects. The student has not identified with the regulation, so it has not become part of the self, and punctuality is not really by choice. Instead, it results from internal coercion. In short, although introjected regulation is internal to the person, it bears more resemblance to external control than to selfdetermined forms of regulation because it involves coercion or seduction and does not entail true choice.

Identified regulation. Identified regulation occurs when the person has come to value the behavior and has identified with and accepted the regulatory process. With identification, the regulatory process has become more fully a part of the self, so the person does the activity more willingly. Behaviors thus regulated are considered more autonomous or selfdetermined than are behaviors regulated by external contingencies or introjects, because identification allows the person to feel a sense of choice or volition about behaving. An example would be a student who willingly does extra work in mathematics because the student believes it is important 
for continuing to succeed at mathematics. The motivation is extrinsic because the activity is performed primarily because of its usefulness or instrumentality for the goal of improving math performance and succeeding in future endeavors, rather than because it is interesting. Nonetheless, the behavior is relatively self-determined because the student does it willingly, for personal reasons, rather than external pressure.

Integrated regulation. The most developmentally advanced form of extrinsic motivation is integrated regulation. In this case the regulatory process is fully integrated with the individual's coherent sense of self; that is, the identifications are reciprocally assimilated with the individual's other values, needs, and identities. For example, a teenager may have one identification with being a good student and one with being a good athlete. It is quite possible that these two identifications could seem conflicting to the student and thus cause tension, even though both are valued by the student. Only when the two identifications have become integrated, when they have become harmonious with each other and with the rest of the student's sense of self, will the internalization process be complete. When regulatory processes are integrated, behavior is an expression of who the individual is - of what is valued by and important to the individual. Behaviors regulated by integrated processes are fully self-determined and appear primarily in adult stages of development.

Integrated regulation bears some relation to intrinsic motivation because both are forms of autonomous self-regulation. Accordingly, the qualities that are associated with intrinsically motivated behavior - such as behaving willingly, being creative, and displaying conceptual or intuitive understanding - can be used as objective markers of the extent to which an extrinsic regulation has become fully integrated. However, intrinsic motivation and integrated regulation are different. Intrinsic motivation is characterized by interest in the activity itself, whereas integrated regulation is characterized by the activity's being personally important for a valued outcome.

Recently, various questionnaires have been constructed to assess regulatory styles (e.g., Blais, Sabourin, Boucher, \& Vallerand, 1990; Ryan \& Connell, 1989; Vallerand, Blais, Brière, \& Pelletier, 1989; Vallerand \& O'Connor, 1991). These questionnaires differ in the age of subjects toward whom they are geared, in the domains to which they refer, and in how many of the six motivational constructs (viz., amotivation, external regulation, introjected regulation, identified regulation, integrated regulation, and intrinsic motivation) they assess. Still, the various scales have the same theoretical underpinnings and have yielded complementary results.

The two scales most relevant to the current discussion of motivation in education are the Academic Self-Regulation Questionnaire (ASRQ; Ryan \& 
Connell, 1989) and the Academic Motivation Scale (AMS; Vallerand et al., 1989). The ASRQ was designed primarily for students in late elementary and middle schools. It includes four subscales measuring the external, introjected, and identified forms of extrinsic motivation and also intrinsic motivation. It focuses on students' motivation to do school-related activities (thus, it does not assess amotivation) and asks them to endorse the degree to which various reasons are true. Integration was not included in the ASRQ because it was assumed these students were too young to have achieved a sense of integration with respect to these activities. The scale presents a stem followed by several reasons, for example "I do my homework because": "I'll get in trouble if I don't" (external); "I'll feel bad about myself if I don't do it" (introjected); "It's important to me to do my homework" (identified); and "I enjoy doing my homework" (intrinsic).

The AMS (Vallerand et al., 1989) also assesses external, introjected, and identified regulation and intrinsic motivation, but also measures amotivation. The AMS was designed for use with college students and uses a format similar to that used by Ryan and Connell (1989) in the ASRQ. In the following sections, we review studies that have used these questionnaires as well as other methods relevant to self-determination.

\section{MOTIVATION AND EDUCATIONAL OUTCOMES}

In several recent studies, self-determined motivation has been linked to various educational outcomes across the age span, from early elementary school to college students. Some of these studies (e.g., Daoust, Vallerand, \& Blais, 1988; Vallerand, 1991; Vallerand \& Bissonnette, in press) have shown that students who had more self-determined forms of motivation for doing schoolwork were more likely to stay in school than students who had less self-determined motivation. Others (e.g., Grolnick, Ryan, \& Deci, in press; Pintrich \& De Groot, 1990) have linked intrinsic motivation and autonomous forms of extrinsic motivation to positive academic performance.

Earlier, we identified conceptual understanding and personal adjustment as the most important educational outcomes. Several recent investigations have focused on the relation of motivation to these outcomes. Grolnick and Ryan (1987) and Grolnick et al. (in press) found that elementary school students who reported more autonomous motivation for doing schoolwork, in general, evidenced greater conceptual learning and better memory than did children who reported less autonomous motivation. An experiment by Benware and Deci (1984), showed similar results with college students. Students who learned text material in order to put it to use reported more intrinsic motivation for learning and showed greater conceptual under- 
standing than did students who learned the material in order to be tested. Similarly, Grolnick and Ryan (1987) found that asking elementary students to learn material in order to be tested on it led to lower interest and poorer conceptual learning than did asking students to learn the material with no mention of a test, even though the test condition led to short-term (less than 1 week) gains in rote recall that had dissipated 1 week later.

Gottfried $(1985,1990)$ measured intrinsic motivation for specific subjects such as mathematics and reading for early-elementary, late-elementary, and junior high students. She reported significant positive correlations between intrinsic motivation and achievement (as measured by standardized achievement tests and by teachers' ratings of achievement). Relations between intrinsic motivation and academic performance were also found in complementary studies by Lloyd and Barenblatt (1984) and Haywood and Burke (1977).

Other studies have focused on personal adjustment - that is, on affective outcomes - as predicted by motivational variables. For example, Vallerand et al. (1989) found that students who had greater intrinsic motivation and identified regulation showed more positive emotions in the classroom, more enjoyment of academic work, and more satisfaction with school than did students whose motivational profiles were less autonomous. Ryan and Connell (1989) also found positive correlations between autonomous regulatory styles and enjoyment of school, whereas they found the more controlling regulatory styles to be associated with greater anxiety and poorer coping with failures. Finally, Deci, Schwartz, Sheinman, and Ryan (1981) found a positive link between student's intrinsic motivation and self-esteem.

It appears from these and other studies (e.g., Connell \& Wellborn, 1990) that students who are intrinsically motivated for doing schoolwork and who have developed more autonomous regulatory styles are more likely to stay in school, to achieve, to evidence conceptual understanding, and to be well adjusted than are students with less self-determined types of motivation. It therefore seems worthwhile to explore the social-contextual conditions that facilitate self-determined forms of motivation.

\section{SOCIAL-CONTEXTUAL INFLUENCES ON STUDENTS}

A great deal of research in the last two decades has explored how various aspects of the social environment affect people's intrinsic motivation and autonomous self-regulation and, in turn, the quality of their performance. A central hypothesis of self-determination theory is that social contexts that support people's being competent, related, and autonomous will promote intentional (i.e., motivated) action, and furthermore, that support for 
autonomy in particular will facilitate that motivated action's being selfdetermined (rather than controlled). Thus, for example, supports for competence (e.g., positive feedback) will enhance motivation in general but will enhance intrinsic motivation and integrated internalization only if it is administered in a way that is autonomy supportive (Ryan, 1982). Similarly, supports for relatedness (e.g., the interpersonal involvement of parents and teachers) will enhance motivation in general but will enhance intrinsic motivation and integrated internalization only if the involved others are autonomy supportive (Grolnick \& Ryan, 1989). To the extent that social contexts do not allow satisfaction of the three basic psychological needs for competence, relatedness, and autonomy, they will diminish motivation, impair the natural developmental process, and lead to alienation and poorer parformanze.

Research testing these hypotheses has been done in the laboratory, as well as in classrooms and homes. In some studies the effects of structural factors or situational events, such as rewards and deadlines, have been explored, whereas in others the influence of general interpersonal climates has been considered. In the majority of studies, intrinsic motivation has been the dependent variable, although in more recent research internalization has been explored by focusing on identified or integrated regulation as outcome variables.

\section{Support for Competence and Relatedness}

According to self-determination theory, supports for competence (e.g., optimal challenges and performance feedback) and for relatedness (e.g., parental involvement and peer acceptance) facilitate motivation. However, such supports will facilitate intrinsic motivation and integrated internalization only to the extent that they are accompanied by autonomy-supportive rather than controlling interpersonal contexts. Although considerable work remains to be done, several studies that we will now review provide some support for these assertions.

The effects of supports for competence and relatedness on motivation and internalization have been investigated in a variety of studies. For example, positive feedback has generally been found to increase intrinsic motivation because it enhances perceived competence (e.g., Blanck, Reis, \& Jackson, 1984; Harackiewicz \& Larson, 1986; Vallerand, 1983), although studies have shown that this enhancement occurs only when the feedback is accompanied by support for autonomy (Fisher, 1978; Ryan, 1982). When the general context is controlling, controlled forms of extrinsic motivation are more likely to result (Deci, Eghrari, Patrick, \& Leone, 1991). Thus, for example, congratulating students for having done well at a self-initiated educational activity is likely to promote feelings of competence and intrinsic 
motivation, whereas praising them for doing what they "should" have done or what you told them to do is likely to lead to their feeling controlled, which in turn would reduce intrinsic motivation and strengthen nonautonomous forms of extrinsic motivation.

Negative feedback, whether interpersonally administered or selfadministered in the form of failure, has generally been found to decrease intrinsic motivation by decreasing perceived competence (Deci, Cascio, \& Krusell, 1973), and some studies indicate that lowered perceived competence can leave people feeling amotivated and helpless (Boggiano \& Barrett, 1985).

Vallerand and Reid $(1984,1988)$ found higher levels of intrinsic motivation after positive than after negative feedback, and path analyses showed that perceived competence mediated between the feedback and the changes in intrinsic motivation. Field studies have also linked perceived competence to intrinsic motivation and to identified self-regulation in both regular education (Grolnick et al., in press; Vallerand et al., 1989) and special education students (Deci, Hodges, Pierson, \& Tomassone, in press).

The effects of adults' interpersonal involvement or relatedness on children's intrinsic motivation and autonomous self-regulation have been explored in only a few studies. There is some evidence that when children are denied the interpersonal involvement they desire, they can lose intrinsic motivation (Anderson, Manoogian, \& Reznick, 1976). Field studies on interpersonal involvement, using interview and questionnaire methods, have also indicated that parents and teachers who are more involved with their children have children who are more motivated and self-determined, particularly when the involvement is accompanied by autonomy support (e.g., Grolnick \& Ryan, 1989; Grolnick et al., in press).

\section{Support for Self-Determination}

Many researchers have explored the effects of autonomy-supportive versus controlling influences on intrinsic motivation and the internalization of regulations. In one set of studies, contextual events such as the offer of a reward, the imposition of a deadline, or the provision of choice were manipulated to examine their effects on intrinsic motivation or internalization. The results suggest which contextual factors tend, on average, to be autonomy supportive and which ones tend to be controlling. They also show that the interpersonal context, as operationalized by the experimenter's interpersonal style, can moderate the effects of specific external events. Thus the effects of specific events such as performance-contingent rewards or limits might be different, depending on whether the experimenter administers them with an autonomy-supportive or a controlling style or intent. A second set of studies was done in schools and homes to investigate 
the relation between general interpersonal contexts (as assessed with questionnaires or interviews) and the intrinsic motivation or internalization of students in those settings. Let us briefly consider each set of studies.

Effects of external events. Rewards such as prizes and money are often used in homes and schools as a means of motivating desired behaviors. Their effects on intrinsic motivation have been explored in several studies. These studies showed that when students received rewards such as monetary payments (Deci, 1971), good-player awards (Lepper, Greene, \& Nisbett, 1973), or prizes (Harackiewicz, 1979) for participating in an interesting activity, they tended to lose interest in and willingness to work on the activity after the rewards were terminated, relative to students who had worked on the activity in the absence of rewards. Similar results were found when people performed an interesting activity in order to avoid a negative consequence (Deci \& Cascio, 1972).

The use of promised rewards or threatened punishment is an ubiquitous motivational strategy. Research on intrinsic motivation (e.g., Ryan, Mims, \& Koestner, 1983) and internalization (e.g., Freedman, 1965) has consistently shown, however, that although these contingencies may serve to control behavior while they are operative, they also tend to undermine intrinsic motivation for interesting tasks and to impede the internalization of regulations for uninteresting tasks (Deci et al., 1991).

Performance evaluations are common in school systems and may take the form of grades, verbal feedback, or written appraisals. Studies have increasingly indicated that when evaluations are emphasized or made salient they will undermine intrinsic motivation (Smith, 1974), conceptual learning (Benware \& Deci, 1984), and creativity (Amabile, 1979). The same has been found for surveillance (e.g., Lepper \& Greene, 1975).

Other external events designed to motivate or control people-including deadlines (Amabile, DeJong, \& Lepper, 1976), imposed goals (Mossholder, 1980), and competition (Deci, Betley, Kahle, Abrams, \& Porac, 1981; Vallerand, Gauvin, \& Halliwell, 1986; Vallerand, Hamel, \& Daoust, 1991) - have similarly been found to decrease intrinsic motivation. The theme common to all of these findings is that each of the mentioned events is typically used to pressure a target person to think, feel, or behave in a specific way. Not surprisingly, then, the event's presence typically signifies to the target person that he or she is being controlled. Being controlled by an external contingency tends to diminish an individual's sense of autonomy. It fosters an external perceived locus of causality and thus decreases intrinsic motivation and/or forestalls internalization.

One might ask whether there are any specifiable contextual events that will promote the experience of self-determination and thus enhance intrinsic motivation or facilitate integrated internalization. Two such events have 
been identified. Zuckerman, Porac, Lathin, Smith, and Deci (1978) found that when college students were given choices about what tasks to engage and how much time to allot to each, they were more intrinsically motivated than were subjects who were assigned the tasks and times. Similar results were obtained with children by Swann and Pittman (1977). Further, in a study of internalization, Deci et al. (1991) found that highlighting choice rather than using a controlling style contributed to subjects' internalizing the regulation of an uninteresting activity.

Other research has also indicated that when asking people to do an uninteresting behavior or to do an interesting behavior in a way that is different from how they want to do it, acknowledging their feelings of not liking the task or not liking the requested way helps them to feel selfdetermined. This resulted in maintained intrinsic motivation (Koestner, Ryan, Bernieri, \& Holt, 1984) and increased internalization (Deci et al., 1991). These studies suggest that in educational settings providing students with the opportunity to participate in the decision process relative to educational activities tend to encourage the self-determined regulation of those activities, which in turn is likely to produce beneficial learning and adjustment outcomes.

Interpersonal contexts. For people involved in the educational process, it is undoubtedly disconcerting to recognize that many of our standard educational structures and practices tend, on the average, to be experienced as controlling and to have negative consequences for the development of autonomous self-regulation. Accordingly, one might wonder how to use these motivationally relevant events and structures in ways that do not have the widely replicated negative effects.

The answer to this question, we believe, lies in the fact that situational events such as rewards and feedback are administered by people within a general interpersonal ambience. Several laboratory studies have shown that the interpersonal style a person uses in administering events greatly influences the events' effects.

In these laboratory studies, events such as positive feedback (Ryan, 1982), performance-contingent rewards (Ryan et al., 1983), and limits (Koestner et al., 1984) were administered in one of two ways-with language and style that were controlling and pressuring (using words like should and must) or with language and style that were noncontrolling and implied choice. The results consistently showed that the manner of presentation was important. For example, even though positive feedback tends to enhance intrinsic motivation, it decreased intrinsic motivation if it was presented in a controlling manner, and even though rewards tend to diminish intrinsic motivation, they maintained or enhanced it if the language or style of presentation was nonpressuring and signified compe- 
tence. A noncontrolling style of presentation has also been shown to contribute to the internalization of regulations and to subsequent autonomous self-regulation (Deci et al., 1991). It thus seems possible that many motivational techniques that tend to be controlling can be used in ways that are nondetrimental. This, however, requires that administrators of such events be able to adopt the recipients' frame of reference and present the events in a way that does not leave the recipients feeling like pawns (deCharms, 1968).

Classroom climates. Results that complement these laboratory experiments have been found in classroom contexts. For example, in one study, Deci, Schwartz, et al. (1981) used an instrument to assess teachers' styles, reasoning that some teachers are oriented toward supporting students' autonomy whereas others are oriented toward controlling students' behavior. Of course, teachers' orientations influence the general classroom climate, and the results revealed that students in classrooms with autonomysupportive teachers displayed more intrinsic motivation, perceived competence, and self-esteem than did students in classrooms with controlling teachers.

In another study, Ryan and Grolnick (1986) assessed elementary school students' perceptions of whether their teachers were controlling or autonomy supportive in the classroom. Students who perceived their teachers to be autonomy supportive reported higher levels of intrinsic motivation, perceived competence, and self-esteem than did students who perceived their teachers to be controlling.

Vallerand (1991) had high school students complete the AMS (Vallerand et al., 1989) along with ratings of the teachers' autonomy supportiveness and their controllingness. Students' perceptions of the autonomy supportiveness of the teachers were positively associated with the selfdetermined forms of motivation (viz., intrinsic motivation and identified self-regulation), and their perceptions of the teachers' controllingness were positively associated with the non-self-determined forms of motivation (viz., external regulation and amotivation).

Finally, in a study by deCharms (1976), some teachers were taught to be more autonomy supportive, and this resulted in enhanced intrinsic motivation and increased achievement in their inner-city students compared with the students of teachers who had not received the training.

Home contexts. Children's motivation toward school activities is influenced not only by their school experiences but also by their home lives. Interview and questionnaire studies have revealed that parental styles concerning autonomy support versus control (as well as involvement) influence students' autonomous self-regulation of schoolwork and in turn 
their school achievement. Parents who were judged by expert raters to be more autonomy supportive and involved (Grolnick \& Ryan, 1989) or who were perceived that way by their elementary school children (Grolnick et al., in press) had children who were more intrinsically motivated and more autonomous in their self-regulation. These children of autonomysupportive and involved parents also performed better in school than did children whose parents were more controlling and uninvolved.

Vallerand (1991) conducted a study with high school students that was similar to the Grolnick et al. (in press) study with elementary children. In it, he found that the more autonomy supportive the students perceived their parents to be, the more self-determined were their motivational profiles; in contrast, the more controlling the students perceived their parents to be, the less self-determined were their motivational profiles. Thus, the effects of home contexts parallel those of the school context.

\section{Student Motivation: Future Directions}

From the outline of self-determination theory and the preceding review of research on intrinsic motivation and internalization, several important directions for future research are apparent. Let us consider a few.

Valuing. For students to be actively engaged in the educational endeavor, they must value learning, achievement, and accomplishment even with respect to topics and activities they do not find interesting. Valuing comes from internalization and integration (Ryan \& Stiller, 1991). Unlike most theorists, we assume people are motivated to internalize the regulation of uninteresting behaviors that are valuable for effective functioning. An initial laboratory experiment (Deci et al., 1991) and an initial field study (Grolnick \& Ryan, 1989) have shown that internalization will proceed most effectively toward self-determined forms of regulation if (a) children understand the personal utility of the activity, (b) they are provided choices about the activity with a minimum of pressure, and (c) their feelings and perspective are acknowledged. These factors support their selfdetermination. When the value of an activity is internalized, people do not necessarily become more interested in the activity or more intrinsically motivated to do it, but they do become willing to do it because of its personal value.

We suggest that the issue of valuing educational activities cannot be fully understood in terms of providing information about expectancies and outcomes because the key to acquiring values is feeling free enough to accept them as one's own. Valuing results from internalization and integration, which require that students are able to feel competent, related, and autonomous while doing the activities. 
Development. Earlier in this article we discussed four regulatory processes relevant to extrinsically motivated behavior (external regulation, introjected regulation, identified regulation, and integration) and we discussed them in terms of the different degrees of self-determination reflected therein. In our empirical work thus far, we have treated these concepts as individual difference variables, assessing the degree to which each person expresses each type of regulatory style. We have done very little work on the developmental emergence of these styles. It is unclear, for example, whether there is a relatively invariant sequence in the emergence of these regulatory styles or whether one style predominates over the others at particular ages.

It is surely the case that in older children and adults, internalization of a particular regulation need not pass from one type to another. A person can either introject or integrate a particular new regulation directly, in a short amount of time, because of a readiness to do so. However, the development of such a readiness may itself be part of a developmental sequence.

Competence and autonomy. The concept of competence is central to several current theories of motivation in education and has been formulated in terms of having control over outcomes (Crandall, Katkovsky, \& Crandall, 1965), being self-efficacious (Bandura, 1977), having confidence (Dweck, 1986), and having the strategies and capacities for success (Skinner, Wellborn, \& Connell, 1990). Our view also gives importance to competence as a prerequisite for motivation, but we believe it is not a sufficient condition for intrinsic motivation, self-initiation, and integration. One can be highly competent and highly motivated, but be regulated externally or by introjects and thus not be autonomous or self-determined. In such cases, the person would be, in the words of deCharms (1976), an efficacious "pawn." Ryan and Connell (1989) reported that, in late elementary school students, both the level of introjection and the level of identification correlated positively and similarly with children's reports of how hard they try in school and also with their parents' ratings of how motivated they are. However, the two styles had other very different correlations. Children who expressed more introjection also expressed more school anxiety and self-blaming, whereas children who expressed more identification also expressed more enjoyment of school and more positive coping with failures. This points to the importance of looking beyond competence and control over outcomes to the sources of initiation and regulation in order to understand effective motivation in school. It points to the importance of autonomy (Ryan, 1982).

Relatedness and autonomy. Ryan (1991; Ryan \& Belmont, 1991; Ryan \& Lynch, 1989) has suggested that autonomy develops most effectively in situations where children and teenagers feel a sense of relatedness 
and closeness to, rather than disaffiliation from, significant adults. A great deal remains to be done to sort out the interaction between adults' being involved with and related to children, on the one hand, and encouraging the autonomy and self-initiation of those children, on the other. An understanding of the independent and interactive contributions of supports for relatedness and autonomy to the development of motivation and selfdetermination will require considerable empirical work.

\section{INFLUENCES ON TEACHERS: EDUCATIONAL POLICY}

It is clear from the research reviewed herein that teachers' behavior, specifically, the degree to which they are autonomy supportive versus controlling, has an important effect on students' motivation and selfdetermination. Therefore it is important to understand whether any factors (other than teacher individual differences) influence the extent to which they will act in autonomy-supportive versus controlling ways. Several studies have been done to investigate this issue, and two important sources of influence have been identified. The first source relates to pressures that are placed on teachers by demands in the school organization, and the second source relates to influences, whether real or imagined, from students.

Deci, Spiegel, Ryan, Koestner, and Kauffman (1982) argued that when teachers are pressured or controlled by their superiors or by the system in general, they are likely to respond by being more controlling with their students. These researchers performed a study in which half the teachers were pressured (by being reminded that it was their responsibility to be sure their students performed up to high standards) and half were not. Results indicated that teachers who had been pressured were dramatically more controlling with their students than those who had not been pressured. Fink, Boggiano, and Barrett (1990) did a complementary study and found similar results. Further, in these studies there was evidence that when the teachers became more controlling the students performed less well in problem-solving activities, both during the teaching session and subsequently.

Pressure from administrators to make sure students perform up to standards is just one kind of pressure that teachers experience. Government agencies, parent groups, and other forces outside the school system bring pressure to bear on school administrators and teachers alike, and all of these intrusions on the teachers' sense of self-determination are likely to lead them to be more controlling with their students. That, in turn, will have negative effects on the students' self-determination, conceptual learning, and personal adjustment. 
The other interesting source of influence on teachers' behavior is the students themselves, or the teachers' beliefs about the students. In one experiment, Jelsma (1982) found that when students (who were actually experimental accomplices) were somewhat fidgety and inattentive during a teaching session, their teachers became more controlling than when the same students were more attentive. It appears that students who are highly motivated and autonomous in school may elicit more autonomy support from their teachers, whereas students who are more distracted and less motivated may elicit more controlling behaviors from the teachers.

A recent experiment by Pelletier and Vallerand (1989) took this reasoning one step further to test the self-fulfilling prophecy effect (e.g., Rosenthal \& Jacobson, 1968; Snyder, 1984) with regard to motivation. Pelletier and Vallerand suggested that if teachers think some students are intrinsically motivated and self-determined, the teachers will be more autonomy supportive with those students, presumably believing the students will regulate themselves. On the other hand, if the teachers think other students are extrinsically motivated and less self-determined, they will be more controlling with those students, presumably believing they have to make the students perform. In the experiment, some "teacher-subjects" were told that the students they were about to teach how to solve puzzles were extrinsically motivated, whereas others were told that their students were intrinisically motivated. Teachers who had been led to believe that the students were extrinsically motivated were very controlling toward the students, which in turn led the students to display low levels of intrinsic motivation toward the puzzles. On the other hand, teachers who thought that they were interacting with intrinsically motivated students were more autonomy supportive, and their students showed high levels of intrinsic motivation. Thus, the teachers' beliefs about the student's motivation (which had been randomly assigned) actually created their own reality.

\section{Educational Policy: Future Directions}

Classrooms are embedded in schools; schools are embedded in communities and society. As the aforementioned research by Deci et al. (1982) suggests, pressures from schools, communities, and society for teachers to be more accountable for students' achievement can lead teachers to be more controlling and thus can be counterproductive for the goals of conceptual understanding and personal growth. Maehr (1991) made the complementary point that classroom practices are dictated to a large degree by school policies. From our perspective, the extent to which the school context is more autonomy supportive, rather than controlling, will directly affect the extent to which teachers support the autonomy of their students. This issue, with its many ramifications, needs much further work, because the school 
system is clearly an appropriate level for much educational reform. This is particularly so because the rhetoric from Washington continues to advocate greater accountability, greater discipline, and increased use of standardized testing, all of which are means of exerting greater pressure and control on the educational process and therefore are likely to have at least some negative consequences.

\section{CONCLUSIONS}

Promoting greater self-determination, that is, a greater sense of choice, more self-initiation of behavior, and greater personal responsibility, is an important developmental goal, and it is becoming increasingly clear that promoting self-determination is the avenue to attaining outcomes such as creativity (Amabile, 1979), cognitive flexibility (McGraw \& McCullers, 1979), and self-esteem (Deci, Schwartz, et al., 1981). In terms of education, it has become ever more apparent that self-determination, in the forms of intrinsic motivation and autonomous internalization, leads to the types of outcomes that are beneficial both to individuals and to society.

We believe that promoting self-determined motivation in students should be given high priority in educational endeavors, and we have focused much of this article on the important elements for doing that. The key elements are what we refer to as autonomy support and interpersonal involvement. When significant adults - most notably, teachers and parents - are involved with students in an autonomy-supportive way, the students will be more likely to retain their natural curiosity (their intrinsic motivation for learning) and to develop autonomous forms of self-regulation through the process of internalization and integration.

Autonomy support by adults begins with taking the child's frame of reference. By understanding a child's motivational and cognitive starting point, we can relate to him or her in a way that encourages internal motivation for engagement in the education enterprise (Connell \& Wellborn, 1990). The specific supports for self-determination we suggest include offering choice, minimizing controls, acknowledging feelings, and making available information that is needed for decision making and for performing the target task. With a general attitude of valuing children's autonomy and by providing the type of autonomy support just mentioned, we stand the greatest chance of bringing about the types of educational contexts that facilitate conceptual understanding, flexible problem solving, personal adjustment, and social responsibility. This is so whether one's analysis focuses on the classroom, the school system, or society. 


\section{ACKNOWLEDGMENTS}

Preparation of this article was supported in part by a research grant from the National Institute of Child Health and Human Development (HD19914) to the Human Motivation Program in the Department of Psychology at the University of Rochester and by research grants from Le Fonds pour la Formation des Chercheurs et l'Aide à la Recherche (FCAR Québec), the Social Science and Humanities Research Council of Canada, and Le Conseil Québécois de la Recherche Sociale to Robert J. Vallerand.

\section{REFERENCES}

Amabile, T. M. (1979). Effects of external evaluations on artistic creativity. Journal of Personality and Social Psychology, 37, 221-233.

Amabile, T. M., Dejong, W., \& Lepper, M. R. (1976). Effects of externally imposed deadlines on subsequent intrinsic motivation. Journal of Personality and Social Psychology, 34, 92-98.

Anderson, R., Manoogian, S. T., \& Reznick, J. S. (1976). The undermining and enhancing of intrinsic motivation in preschool children. Journal of Personality and Social Psychology, 34, 915-922.

Bandura, A. (1977). Self-efficacy: Toward a unifying theory of behavioral change. Psychological Review, 84, 191-215.

Benware, C., \& Deci, E. L. (1984). Quality of learning with an active versus passive motivational set. American Educational Research Journal, 21, 755-765.

Blais, M. R., Sabourin, S., Boucher, C., \& Vallerand, R. J. (1990). Toward a motivational model of couple happiness. Journal of Personality and Social Psychology, 59, 1021-1031.

Blanck, P. D., Reis, H. T., \& Jackson, L. (1984). The effects of verbal reinforcement on intrinsic motivation for sex-linked tasks. Sex Roles, 10, 369-387.

Boggiano, A. K., \& Barrett, M. (1985). Performance and motivational deficits of helplessness: The role of motivational orientations. Journal of Personality and Social Psychology, 49, 1753-1761.

Connell, J. P., \& Wellborn, J. G. (1990). Competence, autonomy and relatedness: A motivational analysis of self-system processes. In M. Gunnar \& A. Sroufe (Eds.), Minnesota symposium on child psychology (Vol. 23, pp. 43-77). Hillsdale, NJ: Lawrence Erlbaum Associates, Inc.

Crandall, V. C., Katkovsky, W., \& Crandall, V. (1965). Children's beliefs in their control of reinforcements in intellectual academic achievement situations. Child Development, 36, 91-109.

Daoust, H., Vallerand, R. J., \& Blais, M. R. (1988). Motivation and education: A look at some important consequences. Canadian Psychology, 29(2a), 172 (abstract).

deCharms, R. (1968). Personal causation: The internal affective determinants of behavior. New York: Academic.

deCharms, R. (1976). Enhancing motivation: Change in the classroom. New York: Irvington.

Deci, E. L. (1971). Effects of externally mediated rewards on intrinsic motivation. Journal of Personality and Social Psychology, 18, 105-115.

Deci, E. L. (in press). On the nature and functions of motivation theories. Psychological Science. 
Deci, E. L., Betley, G., Kahle, J., Abrams, L., \& Porac, J. (1981). When trying to win: Competition and intrinsic motivation. Personality and Social Psychology Bulletin, 7, 79-83.

Deci, E. L., \& Cascio, W. F. (1972, April). Changes in intrinsic motivation as a function of negative feedback and threats. Paper presented at the meeting of the Eastern Psychological Association, Boston.

Deci, E. L., Cascio, W. F., \& Krusell, J. (1973, May). Sex differences, verbal reinforcement, and intrinsic motivation. Paper presented at the meeting of the Eastern Psychological Association, Washington, DC.

Deci, E. L., Eghrari, H., Patrick, B. C., \& Leone, D. R. (1991). Facilitating internalization: The self-determination theory perspective. Unpublished manuscript, University of Rochester, Rochester, NY.

Deci, E. L., Hodges, R., Pierson, L., \& Tomassone, J. (in press). Autonomy and competence as motivatial factors in students with learning disabilities and emotional handicaps. Journal of Learning Disabilities.

Deci, E. L., \& Ryan, R. M. (1985). Intrinsic motivation and self-determination in human behavior. New York: Plenum.

Deci, E. L., \& Ryan, R. M. (1991). A motivational approach to self: Integration in personality. In R. Dienstbier (Ed.), Nebraska symposium on motivation: Vol. 38, Perspectives on motivation (pp. 237-288). Lincoln: University of Nebraska Press.

Deci, E. L., Schwartz, A. J., Sheinman, L., \& Ryan, R. M. (1981). An instrument to assess adults' orientation toward control versus autonomy with children: Reflections on intrinsic motivation and perceived competence. Journal of Educational Psychology, 73, 642-650.

Deci, E. L., Spiegel, N. H., Ryan, R. M., Koestner, R., \& Kauffman, M. (1982). The effects of performance standards on teaching styles: The behavior of controlling teachers. Journal of Educational Psychology, 74, 852 859.

Dweck, C. S. (1986). Motivational processes affecting learning. American Psychologist, 41, 1040-1048.

Eccles, J. S. (1983). Expectancies, values, and academic behaviors. In J. T. Spence (Ed.), Achievement and achievement motivation (pp. 75-146). San Francisco: Freeman.

Fisher, C. F. (1978). The effects of personal control, competence and extrinsic reward systems on intrinsic motivation. Organizational Behavior and Human Performance, 21, 273-288.

Flink, C., Boggiano, A. K., \& Barrett, M. (1990). Controlling teaching strategies: Undermining children's self-determination and performance. Journal of Personality and Social Psychology, 59, 916-924.

Freedman, J. L. (1965). Long-term cognitive dissonance. Journal of Experimental Social Psychology, 1, 145-155.

Gottfried, A. E. (1985). Academic intrinsic motivation in elementary and junior high school students. Journal of Educational Psychology, 20, 205-215.

Gottfried, A. E. (1990). Academic intrinsic motivation in young elementary school children. Journal of Educational Psychology, 82, 525-538.

Grolnick, W. S., \& Ryan, R. M. (1987). Autonomy in children's learning: An experimental and individual difference investigation. Journal of Personality and Social Psychology, 52, 890-898.

Grolnick, W. S., \& Ryan, R. M. (1989). Parent styles associated with children's self-regulation and competence in school. Journal of Educational Psychology, 81, 143-154.

Grolnick, W. S., Ryan, R. M., \& Deci, E. L. (in press). The inner resources for school achievement: Motivational mediators of children's perceptions of their parents. Journal of Educational Psychology.

Harackiewicz, J. M. (1979). The effects of reward contingency and performance feedback on 
intrinsic motivation. Journal of Personality and Social Psychology, 37, 1352-1363.

Harackiewicz, J. M., \& Larson, J. R. (1986). Managing motivation: The impact of supervisor feedback on subordinate task interest. Journal of Personality and Social Psychology, 51, 547-556.

Haywood, H. C., \& Burke, W. P. (1977). Development of individual differences in intrinsic motivation. In I. C. Uzgiris \& F. Weizmann (Eds.), The structuring of experience (pp. 235-263). New York: Plenum.

Heider, F. (1958). The psychology of interpersonal relations. New York: Wiley.

Jelsma, B. M. (1982). Adult control behaviors: The interaction between orientation toward control in women and activity level of children. Unpublished doctoral dissertation, University of Rochester, Rochester, NY.

Koestner, R., Ryan, R. M., Bernieri, F., \& Holt, K. (1984). Setting limits in children's behavior: The differential effects of controlling versus informational styles on intrinsic motivation and creativity. Journal of Personality, 52, 233-248.

Lepper, M. R., \& Greene, D. (1975). Turning play into work: Effects of adult surveillance and extrinsic rewards on children's intrinsic motivation. Journal of Personality and Social Psychology, 31, 479-486.

Lepper, M. R., Greene, D., \& Nisbett, R. E. (1973). Undermining children's intrinsíc interest with extrinsic rewards: A test of the "overjustification" hypothesis. Journal of Personality and Social Psychology, 28, 129-137.

Lewin, K. (1951). Intention, will, and need. In D. Rapaport (Ed.), Organization and pathology of thought (pp. 95-153). New York: Columbia University Press.

Lloyd, J., \& Barenblatt, L. (1984). Intrinsic intellectuality: Its relation to social class, intelligence, and achievement. Journal of Personality and Social Psychology, 46, 646-654.

Maehr, M. L. (1991, April). Changing the schools: A word to school leaders about enhancing student investment in learning. Paper presented at the annual conference of the American Educational Research Association, Chicago.

McGraw, K. O., \& McCullers, J. C. (1979). Evidence of a detrimental effect of extrinsic incentives on breaking a mental set. Journal of Experimental Social Psychology, 15, 285-294.

Mossholder, K. W. (1980). Effects of externally mediated goal setting on intrinsic motivation: A laboratory experiment. Journal of Applied Psychology, 65, 202-210.

Pelletier, L. G., \& Vallerand, R. J. (1989). Behavioral confirmation in social interaction: Effects of teachers' expectancies on students' intrinsic motivation. Canadian Psychology, 30(2a), 404 (abstract).

Pintrich, P. R., \& De Groot, E. V. (1990). Motivational and self-regulated learning. Journal of Educational Psychology, 82, 33-40.

Rosenthal, R., \& Jacobson, L. (1968). Pygmalion in the classroom: Teacher expectation and pupils' intellectual development. New York: Holt, Rinehart \& Winston.

Rotter, J. B. (1966). Generalized expectancies for internal versus external control of reinforcement. Psychological Monographs, 80(1, Whole No. 609).

Ryan, R. M. (1982). Control and information in the intrapersonal sphere: An extension of cognitive evaluation theory. Journal of Personality and Social Psychology, 43, 450-461.

Ryan, R. M. (1991). The nature of the self in autonomy and relatedness. In G. R. Goethals \& J. Strauss (Eds.), Multidisciplinary perspectives on the self (pp. 208-238). New York: Springer-Verlag.

Ryan, R. M., \& Belmont, M. (1991, April). Autonomy and relatedness as fundamental motives in learning and development. Paper presented at the annual conference of the American Educational Research Association, Chicago.

Ryan, R. M., \& Connell, J. P. (1989). Perceived locus of causality and internalization: 
Examining reasons for acting in two domains. Journal of Personality and Social Psychology, 57, 749-761.

Ryan, R. M., \& Grolnick, W. S. (1986). Origins and pawns in the classroom: Self-report and projective assessments of individual differences in children's perceptions. Journal of Personality and Social Psychology, 50, 550-558.

Ryan, R. M., \& Lynch, J. (1989). Emotional autonomy versus detachment: Revisiting the vicissitudes of adolescence and young adulthood. Child Development, 60, 340-356.

Ryan, R. M., Mims, V., \& Koestner, R. (1983). Relation of reward contingency and interpersonal context to intrinsic motivation: A review and test using cognitive evaluation theory. Journal of Personality and Social Psychology, 45, 736-750.

Ryan, R. M., \& Stiller, J. (1991). The social contexts of internalization: Parent and teacher influences on autonomy, motivation and learning. In P. R. Pintrich \& M. L. Maehr (Eds.), Advances in motivation and achievement: Vol. 7, Goals and self-regulatory processes (pp. 115-149). Greenwich, CT: JAI.

Schafer, R. (1968). Aspects of internalization. New York: International Universities Press.

Seligman, M. E. P. (1975). Helplessness: On depression, development, and death. San Francisco: Freeman.

Skinner, E., Wellborn, J. G., \& Connell, J. P. (1990). What it takes to do well in school and whether I've got it: A process model of perceived control and children's engagement and achievement in school. Journal of Educational Psychology, 82, 22-32.

Smith, W. E. (1974). The effects of social and monetary rewards on intrinsic motivation. Unpublished doctoral dissertation, Cornell University, Ithaca, NY.

Snyder, M. (1984). When beliefs create reality. In L. Berkowitz (Ed.), Advances in experimental social psychology (Vol. 18, pp. 257-305). New York: Academic.

Swann, W. B., \& Pittman, T. S. (1977). Initiating play activity of children: The moderating influence of verbal cues on intrinsic motivation. Child Development, 48, 1128-1132.

Vallerand, R. J. (1983). Effect of differential amounts of positive verbal feedback on the intrinsic motivation of male hockey players. Journal of Sport Psychology, 5, 100-107.

Vallerand, R. J. (1991). A motivational analysis of high school dropout. Unpublished manuscript, University of Quebec at Montreal, Montreal, Canada.

Vallerand, R. J., \& Bissonnette, R. (in press). Intrinsic, extrinsic, and amotivational styles as predictors of behavior: A prospective study. Journal of Personality.

Vallerand, R. J., Blais, M. R., Brière, N. M., \& Pelletier, L. G. (1989). Construction et validation de l'Echelle de Motivation en Education [Construction and validation of the Academic Motivation Scale]. Canadian Journal of Behavioral Sciences, 21, 323-349.

Vallerand, R. J., Gauvin, L. I., \& Halliwell, W. R. (1986). Negative effects of competition on children's intrinsic motivation. Journal of Social Psychology, 126, 649-657.

Vallerand, R. J., Hamel, M., \& Daoust, H. (1991). Cooperation and competition: A test of their relative effects on intrinsic motivation. Unpublished manuscript, University of Quebec at Montreal, Montreal, Canada.

Vallerand, R. J., \& O'Connor, B. P. (1991). Construction et validation de l'Echelle de Motivation pour les Personnes Agées [Construction and validation of the Motivation Scale for the Elderly]. International Journal of Psychology, 26, 219-240.

Vallerand, R. J., \& Reid, G. (1984). On the causal effects of perceived competence on intrinsic motivation: A test of cognitive evaluation theory. Journal of Sport Psychology, 6, 94-102.

Vallerand, R. J., \& Reid, G. (1988). On the relative effects of positive and negative verbal feedback on males and females' intrinsic motivation. Canadian Journal of Behavioral Sciences, 20, 239-250.

Zuckerman, M., Porac, J., Lathin, D., Smith, R., \& Deci, E. L. (1978). On the importance of self-determination for intrinsically motivated behavior. Personality and Social Psychology Bulletin, 4, 443-446. 